\title{
Racism at GDC: BDA calls for proper safeguards to protect all registrants
}

The British Dental Association has called on the General Dental Council (GDC) to ensure it offers meaningful protection to all registrants, following the suspension of a Practice Committee Member for making racially motivated comments.

Rashpal Singh Mondair, a former chair of the Committee, now faces an immediate six-month suspension, to be followed by a review. On 1 August 2018, while acting as a Practice Committee Member, he made comments along the lines of 'this is going to sound racist but...' stating he would not want to be treated by a dentist from Africa. Witnesses suggest similar views were expressed concerning dentists from both Eastern Europe and Asia.

The GDC has already recognised that these comments had the potential to jeopardise the impartiality of the regulatory process, and risked the integrity and fairness of decision-making.

The regulator has been undertaking work on EDI and published its strategy a few months ago. Within this, it has made a commitment to analyse over-representation in Fitness to Practise cases. Dentist leaders are now seeking urgent clarity that this unprofessional behaviour has not impacted the treatment of any registrants to date and that safeguards are in place to ensure fair and equitable treatment for all.

Shareena Ilyas, Chair of the British Dental Association's Education, Ethics and the Dental Team Working Group said: 'These sickening comments have absolutely no place in this profession, let alone in our professional regulator.

'The General Dental Council has taken the right course of action. However, this raises serious questions about decisions taken over the course of years.

'An individual harbouring poisonous views was free to hold a privileged position at a health watchdog. Ethnic minority dentists are already more likely to expect referrals from patients. We need cast-iron assurances that safeguards are now in place to ensure fair treatment for all when complaints reach the GDC.'

In response to questions relating to the case, a spokesperson for the General
Dental Council said: 'We welcome the decision of the independent fitness to practise panel to suspend Rashpal Mondair's registration as a dentist, and we appreciate the BDA's recognition that we have taken the right course of action in this case - both in acting immediately to remove the individual from acting as a panel member, and in progressing the fitness to practise investigation.

'Of course, we also agree that racism has absolutely no place in dentistry, including in how the professions are regulated.

'The system has assurance mechanisms in place to ensure that the process operates fairly. Independent fitness to practise panels are always made up of three people and no one panellist has undue influence over the others. Panellists are scrutinised at selection, receive diversity and unconscious bias training at induction and then again each year.

'Fitness to Practise outcomes are also scrutinised in multiple ways, both internally at the GDC and through external audit and review.'

\section{Dentistry celebrated during a year of challenge and change}

Twenty individuals are being celebrated in the latest round of the prestigious BDA Honours and Awards, for their outstanding achievements, their commitment to the BDA, and their work for the dental profession.

From all sections of the profession, general practice, through to community and hospital dentistry, and across the four nations, the BDA is proud to honour these people. The Association also recognises the commitment and dedication of the BDA staff to our members and the profession during the COVID-19 crisis, and has awarded a Certificate of Merit for Services to the Association.

Roz McMullan Chair of the BDA's Honours and Awards Committee said: 'I am delighted to see these people honoured for their hard work and commitment to dentistry.

'Through these times of immense challenge and change, we are proud to be able to highlight the work of those who have gone above and beyond, making our profession better. We are proud to showcase those who have supported our causes, gone over and above for the profession, and/ or given exemplary patient care.

'During

2021/22, we want

to find dentists

who have shown

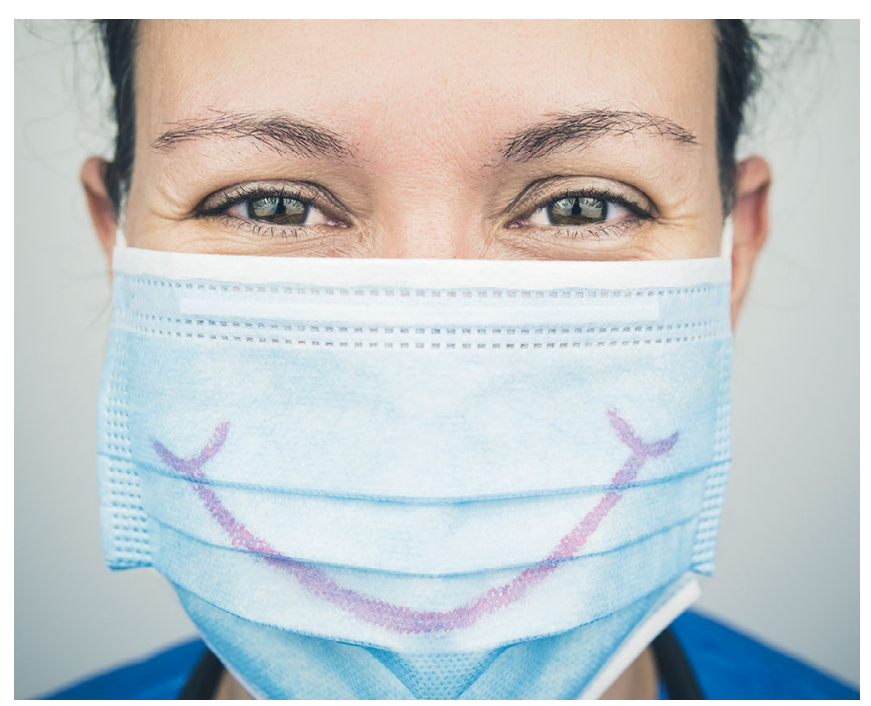

a commitment

to advancing dentistry. We strongly encourage nominations from all areas of the profession - please consider putting forward a colleague/s who you think deserve recognition for what they do.'
The deadline for the next round of nominations is 27 May 2022.

Nominations for the Joy Harrild Award for Young Dentists should be submitted by 29 April 2022. 